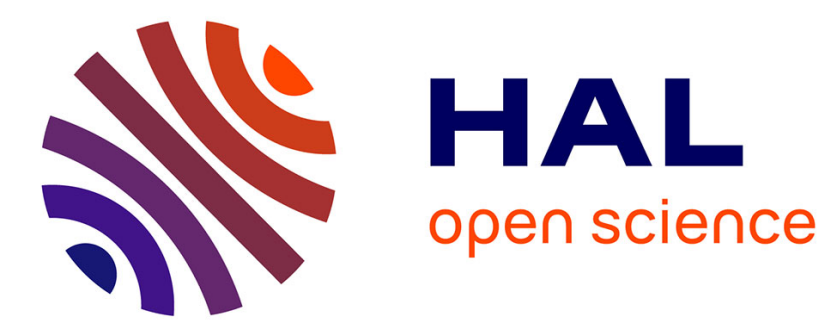

\title{
Internal stress reduction in filament wound composite pipes by humid conditioning: numerical simulation
}

\author{
Frédéric Jacquemin, Alain Vautrin, Ronald Guillén
}

\section{To cite this version:}

Frédéric Jacquemin, Alain Vautrin, Ronald Guillén. Internal stress reduction in filament wound composite pipes by humid conditioning: numerical simulation. International Conference on Processing and Manufacturing of Advanced Materials, 2003, Madrid, Spain. 10.4028/www.scientific.net/MSF.426432.2089 . hal-01008358

\section{HAL Id: hal-01008358 https://hal.science/hal-01008358}

Submitted on 1 Jul 2018

HAL is a multi-disciplinary open access archive for the deposit and dissemination of scientific research documents, whether they are published or not. The documents may come from teaching and research institutions in France or abroad, or from public or private research centers.
L'archive ouverte pluridisciplinaire HAL, est destinée au dépôt et à la diffusion de documents scientifiques de niveau recherche, publiés ou non, émanant des établissements d'enseignement et de recherche français ou étrangers, des laboratoires publics ou privés. 


\title{
Internal stress reduction in filament wound composite pipes
}

\section{by humid conditioning : numerical simulation}

\author{
F. Jacquemin ${ }^{1}$, A. Vautrin ${ }^{2}$ and R. Guillén ${ }^{1}$ \\ ${ }^{1}$ Laboratoire d'Applications des Matériaux à la Mécanique, IUT de Saint-Nazaire - Université de \\ Nantes, 44600 Saint-Nazaire, France \\ ${ }^{2}$ Mechanical and Materials Engineering Department, Ecole Nationale Supérieure des Mines de \\ Saint-Etienne, 42000 Sant-Etienne, France
}

Keywords: Internal stress, hygrothermal treatment, filament winding process, polymer composite pipes.

\begin{abstract}
The paper introduces a new approach which tends to lower the internal stress state within composite pipe walls by using special post-cure hygrothermal treatment. Residual curing stresses in polymer composites are particularly critical in dry conditions, it is proved that an easy way to limit their effect on the material integrity is to introduce hygrothermal stresses. The residual stresses define the initial state of the pipe before it's service life. Usual ambient conditions generate internal stresses which add to the residual manufacturing stresses. It is shown that particularly hygrothermal conditions introduced just after the manufacturing can induce transient stresses which finally will reduce the global stresses. The proposed approach makes it possible to check the influence of timevariable process temperature and pressure, and hygrothermal in-service conditions on polymer matrix composites behavior.
\end{abstract}

\section{Introduction}

The composite pipes are usually manufactured by filament winding process. The filament winding process is commonly composed of three steps : (1) winding the composite tows onto a mandrel, (2) curing, and (3) cool-down and removal of the mandrel. After winding, the assembly composed of the mandrel and the composite pipe is introduced in an autoclave to cure the epoxy resin according to a prescribed temperature and pressure history [1]. The stress free state is supposed to be achieved at the cure temperature then there is no stress development prior to cool-down. In thin composites a uniform through-the-thickness temperature distribution assumption is justified. Such an approach is not appropriate for predicting the process-induced stresses in thick thermoset composites where complex temperature develops during the manufacturing process [2]. The residual stresses in the pipe wall, due to non-uniform temperature fields, are computed within the framework of thermoelasticity. Special attention is then paid to the particular effect of the mandrel thickness on the residual stress development. When curing is completed, the mandrel is removed and the pipe is submitted to the environmental conditions. Ambient conditions generate internal stresses which add to the residual manufacturing stresses. Such residual stress growth may damage pipes manufactured by using thick mandrels. The scope of the paper is to show that the introduction of particular hygrothermal conditions just after the manufacturing process induce transient stresses which counteract the residual curing stresses.

\section{Manufacturing process}

Temperature field.

We consider a pipe made up of $n$ perfectly bonded plies, whose inner and outer radii are $a$ and $b$ respectively, manufactured by filament winding process onto a mandrel. Any ply $i$ of it is a cylinder whose inner and outer radii are $r_{i}$ and $r_{i+l}$ respectively. The pipe and the mandrel are initially at the same uniform temperature $T_{0}$. Thermal transfers take place on the external face that are controlled 
by a coefficient of exchange $h$ kept constant. The autoclave temperature $T(t)$ follow the cure cycle. It is assumed that no heat transfer occurs at the inside of the mandrel [3]. Conditions of continuity of the temperature and heat flux are prescribed at ply-interfaces.

The temperature field in ply $i$ (the internal ply being the mandrel) is solution of the equation set bellow, with Fourier's equation (1) and boundary and initial conditions (2) :

$$
\begin{aligned}
& \frac{\partial \mathrm{T}_{\mathrm{i}}}{\partial \mathrm{t}}=\mathrm{k}_{\mathrm{i}}\left(\frac{\partial^{2} \mathrm{~T}_{\mathrm{i}}}{\partial \mathrm{r}^{2}}+\frac{1}{\mathrm{r}} \frac{\partial \mathrm{T}_{\mathrm{i}}}{\partial \mathrm{r}}\right), \mathrm{a}<\mathrm{r}<\mathrm{b}, \mathrm{i}=1 \text { to } \mathrm{n} \\
& \left\{\begin{array}{l}
\mathrm{T}_{\mathrm{i}}\left(\mathrm{r}_{\mathrm{i}}, \mathrm{t}\right)=\mathrm{T}_{\mathrm{i}+1}\left(\mathrm{r}_{\mathrm{i}}, \mathrm{t}\right) \\
\lambda_{\mathrm{i}} \frac{\partial \mathrm{T}_{\mathrm{i}}\left(\mathrm{r}_{\mathrm{i}}, \mathrm{t}\right)}{\partial \mathrm{r}}=\lambda_{\mathrm{i}+1} \frac{\partial \mathrm{T}_{\mathrm{i}+1}\left(\mathrm{r}_{\mathrm{i}}, \mathrm{t}\right)}{\partial \mathrm{r}} \\
\frac{\partial \mathrm{T}_{1}(\mathrm{a}, \mathrm{t})}{\partial \mathrm{r}}=0 \\
\frac{\partial \mathrm{T}_{\mathrm{n}}(\mathrm{b}, \mathrm{t})}{\partial \mathrm{r}}-\mathrm{h}\left(\mathrm{T}(\mathrm{t})-\mathrm{T}_{\mathrm{n}}(\mathrm{b}, \mathrm{t})\right)=0 \\
\mathrm{~T}_{\mathrm{i}}(\mathrm{r}, 0)=\mathrm{T}_{0}
\end{array}\right.
\end{aligned}
$$

The thermal field, in the composite pipe during the cool-down, is determined by using a finite difference scheme.

\section{Process-induced stresses.}

The residual stresses for every ply at any time are calculated by using the classical equations of solid mechanics : constitutive laws of thermoelastic orthotropic materials (3), strain-displacement relationship, compatibility and equilibrium equations and boundary conditions [4].

$$
\sigma=\mathbf{L}:\left(\varepsilon-\alpha\left(\mathrm{T}-\mathrm{T}_{0}\right)\right)
$$

At the beginning of the cool-down, let us consider a stress-free state. Moreover $\alpha$ and $\mathbf{L}$, respectively the tensors of thermal expansion coefficients and stiffnesses, are assumed to be constants.

The axial and circumferential components of the displacement field of the ith ply, respectively $u$ and $v$, are then express (4):

$$
\left\{\begin{array}{l}
u=R_{1} x \\
v=R_{2} x r
\end{array}\right.
$$

The radial component of the displacement field $w$ satisfies the following equation :

$$
\begin{gathered}
r^{2} \frac{\partial^{2} \mathrm{w}}{\partial \mathrm{r}^{2}}+\mathrm{r} \frac{\partial \mathrm{w}}{\partial \mathrm{r}}-\frac{\mathrm{L}_{\theta \theta}}{\mathrm{L}_{\mathrm{rr}}} \mathrm{w}=\frac{\mathrm{r}\left[\left(\mathrm{L}_{\mathrm{x} \theta}-\mathrm{L}_{\mathrm{xr}}\right) \mathrm{R}_{1}+\left(\mathrm{L}_{\mathrm{s} \theta}-2 \mathrm{~L}_{\mathrm{rs}}\right) \mathrm{R}_{2} \mathrm{r}\right]}{\mathrm{L}_{\mathrm{rr}}} \\
+\frac{\mathrm{r}\left[\left(\mathrm{K}_{1}-\mathrm{K}_{2}\right)\left(\mathrm{T}-\mathrm{T}_{0}\right)+\mathrm{K}_{1} \mathrm{r} \frac{\partial \mathrm{T}}{\partial \mathrm{r}}\right]}{\mathrm{L}_{\mathrm{rr}}}
\end{gathered}
$$

with, $\mathrm{K}_{1}=\mathrm{L}_{\mathrm{xr}} \alpha_{\mathrm{xx}}+\mathrm{L}_{\mathrm{r} \theta} \alpha_{\theta \theta}+\mathrm{L}_{\mathrm{rr}} \alpha_{\mathrm{rr}}+\mathrm{L}_{\mathrm{rs}} \alpha_{\mathrm{x} \theta}, \mathrm{K}_{2}=\mathrm{L}_{\mathrm{x} \theta} \alpha_{\mathrm{xx}}+\mathrm{L}_{\theta \theta} \alpha_{\theta \theta}+\mathrm{L}_{\mathrm{r} \theta} \alpha_{\mathrm{rr}}+\mathrm{L}_{\mathrm{s} \theta} \alpha_{\mathrm{x} \theta}$. 
The temperature field is determined by using a finite difference scheme. To propose a close form solution of the displacement, we subdivide the mandrel-composite structure and assume on each subdivision a parabolic temperature field (6) :

$$
\mathrm{T}_{\mathrm{i}}=\mathrm{A}_{\mathrm{i}} \mathrm{r}^{2}+\mathrm{B}_{\mathrm{i}} \mathrm{r}+\mathrm{C}_{\mathrm{i}}
$$

Thus, we obtain the radial component of the displacement field, solution of the equation (5), for each subdivision :

$$
\begin{aligned}
& \mathrm{w}=\mathrm{R}_{3} \mathrm{r} \sqrt{\frac{\mathrm{L}_{\theta \theta}}{\mathrm{L}_{\mathrm{rr}}}}+\mathrm{R}_{4} \mathrm{r} \sqrt{\frac{\mathrm{L}_{\theta \theta}}{\mathrm{L}_{\mathrm{rr}}}}+\frac{\left(\mathrm{L}_{\mathrm{x} \theta}-\mathrm{L}_{\mathrm{xr}}\right) \mathrm{R}_{1} \mathrm{r}}{\mathrm{L}_{\mathrm{rr}}\left(1-\frac{\mathrm{L}_{\theta \theta}}{\mathrm{L}_{\mathrm{rr}}}\right)}+\frac{\left(\mathrm{L}_{\mathrm{s} \theta}-2 \mathrm{~L}_{\mathrm{rs}}\right) \mathrm{R}_{2} \mathrm{r}^{2}}{\mathrm{~L}_{\mathrm{rr}}\left(4-\frac{\mathrm{L}_{\theta \theta}}{\mathrm{L}_{\mathrm{rr}}}\right)}-\frac{\left(\mathrm{K}_{1}-\mathrm{K}_{2}\right) \mathrm{T}_{0} \mathrm{r}}{\mathrm{L}_{\mathrm{rr}}\left(1-\frac{\mathrm{L}_{\theta \theta}}{\mathrm{L}_{\mathrm{rr}}}\right)} \\
& +\frac{\mathrm{K}_{1}}{\mathrm{~L}_{\mathrm{rr}}}\left[\frac{\mathrm{B}_{\mathrm{i}} \mathrm{r}^{2}}{\left(4-\frac{\mathrm{L}_{\theta \theta}}{\mathrm{L}_{\mathrm{rr}}}\right)}+\frac{2 \mathrm{~A}_{\mathrm{i}} \mathrm{r}^{3}}{\left(9-\frac{\mathrm{L}_{\theta \theta}}{\mathrm{L}_{\mathrm{rr}}}\right)}\right]+\frac{\left(\mathrm{K}_{1}-\mathrm{K}_{2}\right)}{\mathrm{L}_{\mathrm{rr}}}\left[\frac{\mathrm{C}_{\mathrm{i}} \mathrm{r}}{\left(1-\frac{\mathrm{L}_{\theta \theta}}{\mathrm{L}_{\mathrm{rr}}}\right)}+\frac{\mathrm{B}_{\mathrm{i}} \mathrm{r}^{2}}{\left(4-\frac{\mathrm{L}_{\theta \theta}}{\mathrm{L}_{\mathrm{rr}}}\right)}+\frac{\mathrm{A}_{\mathrm{i}} \mathrm{r}^{3}}{\left(9-\frac{\mathrm{L}_{\theta \theta}}{\mathrm{L}_{\mathrm{rr}}}\right)}\right]
\end{aligned}
$$

Finally for n-layer tube the displacement field depends on $4 n$ constants $\left(R_{1}, R_{2}, R_{3}\right.$ and $\left.R_{4}\right)$ to be determined. The constants are calculated from the following conditions : continuity of the displacement components at each interply; global force balance of the cylinder; continuity of the normal stress at each interply and its nullity on the internal surface and an autoclave pressure applied on the external surface.

\section{Internal stresses generated by the ambient conditions}

When curing is completed, the mandrel is removed and the pipe is submitted to the environmental conditions. Ambient conditions generate internal stresses which add to the residual manufacturing stresses. The internal stresses in the pipe wall are computed within the framework of hygro-thermo-elasticity. We consider an orthotropic hygrothermoelastic constitutive law, straindisplacement relationship and compatibility and equilibrium equations [4]. To calculate the unknown constants, $4 n$ constants for n-layer tube, we applied identical relations to the determination of the process-induced stresses but with the nullity of the normal internal stress on the two lateral surfaces of the composite pipe.

\section{Example}

We consider a thick walled carbon-epoxy (T300/5208) pipe made up of 20 plies of equal thickness, the inner and outer radii being respectively $75 \mathrm{~mm}$ and $90 \mathrm{~mm}$. The lamination sequence (corresponding to high buckling strength) studied is $\left[90_{6} / 60 /-60 /(30 /-30)_{5} / 60 /-60 / 90_{2}\right]$. An aluminium mandrel $6061-\mathrm{T} 6$ is used for the manufacturing process [5]. The mechanical properties of the composite (T300/5208) and aluminium mandrel are respectively presented in Tables 1 and 2. The cure temperature and room temperature are $180^{\circ} \mathrm{C}$ and $20^{\circ} \mathrm{C}$ respectively. The cooling rate is $3^{\circ} \mathrm{C} / \mathrm{min}$. The thermal properties of the composite (T300/5208) and aluminium mandrel are presented in Table 3. The thickness of the mandrel hm is chosen to be equal to one-third, one-fifth, one-seventh or one-ninth of the total thickness $h$ (mandrel + composite). 
Table 1 : Mechanical properties in the reference frame linked to the fibres $(1,2,3)$

\begin{tabular}{lccccccc}
\hline Material & $\mathrm{E}_{1}[\mathrm{Gpa}]$ & $\mathrm{E}_{2}, \mathrm{E}_{3}[\mathrm{GPa}]$ & $v_{12}, v_{13}$ & $v_{23}$ & $\mathrm{G}_{12}[\mathrm{GPa}]$ & $\alpha_{1}\left[\mathrm{~K}^{-1}\right]$ & $\alpha_{2}, \alpha_{3}\left[\mathrm{~K}^{-1}\right]$ \\
\hline T300/5208 & 181 & 10,3 & 0,28 & 0,43 & 7,17 & $0,02.10^{-6}$ & $22,5.10^{-6}$ \\
\hline
\end{tabular}

Table 2 : Mechanical properties for aluminium mandrel (6061-T6)

\begin{tabular}{cccc} 
Material & $\mathrm{E}[\mathrm{GPa}]$ & $v$ & $\alpha\left[\mathrm{K}^{-1}\right]$ \\
\hline Aluminium & 72.5 & 0,3 & $23.6 .10^{-6}$ \\
\hline
\end{tabular}

Table 3 : Thermal properties of the composite (T300/5208) and aluminium mandrel (6061-T6)

\begin{tabular}{lcccc}
\hline Materials & $\lambda\left[\mathrm{W} \cdot \mathrm{m}^{-1} \cdot \mathrm{K}^{-1}\right]$ & $\rho\left[\mathrm{kg} \cdot \mathrm{m}^{-3}\right]$ & $\mathrm{c}\left[\mathrm{J} \cdot \mathrm{kg}^{-1} \cdot \mathrm{K}^{-1}\right]$ & $\mathrm{h}\left[\mathrm{W} \cdot \mathrm{m}^{-2} \cdot \mathrm{k}^{-1}\right]$ \\
\hline T300/5208 & 0,7 & 1590 & 857 & 50 \\
\hline Aluminium & 180 & 2700 & 964 & \\
\hline
\end{tabular}

The use of the Tsai strength criterion allows us to estimate the internal stresses versus the ply resistance. The tensile failure stresses in the longitudinal, normal and transverse direction denoted respectively $X, Y, Z$ are reported in Table 4 . The corresponding failure stresses for compression are $X^{\prime}, Y^{\prime}, Z^{\prime}$ and $S$ stands for the plane shear failure stress. These strengths are assumed not to depend on humidity and temperature. $R$, the strength factor derived from the Tsai strength criterion, stands for the ratio between the ultimate stress and the applied stress. Therefore, the failure occurs when $R$ is less or equal to 1 .

Table $4:$ T300/5208 strengths [6]

\begin{tabular}{lcccc}
\hline Strengths [MPa] & $X, X^{\prime}$ & $Y, Z$ & $Y^{\prime}, Z^{\prime}$ & $S$ \\
\hline T300/5208 & 1500 & 40 & 246 & 68 \\
\hline
\end{tabular}

The cool-down from the cure temperature $\left(180^{\circ} \mathrm{C}\right)$ to the room temperature $\left(20^{\circ} \mathrm{C}\right)$ for a cooling rate of $3^{\circ} \mathrm{C} / \mathrm{min}$ takes $3200 \mathrm{~s}$. The thermal fields at the end of the cool-down, for different thickness of the mandrel, are plotted in Fig. 1(a). There is a considerable lag between the tube and autoclave temperatures, especially at the inner surface where no heat transfer occurs. Thermal gradients are growing functions of the mandrel thickness. Fig. 1(b) shows that the minimum strength factor is reached at the inner surface $\left(90^{\circ}\right.$ layer). Even if the strength factor remains encouraging for the composite plies, we recommend the utilization of thin mandrel which one the strength factor is higher on the inner surface.

When curing is completed, the mandrel is removed and the pipe is submitted to the environmental conditions : a temperature of $20^{\circ} \mathrm{C}$ and a relative humidity of $50 \%$. Since the temperature diffusion speed exceeds the moisture diffusion one by several orders, it is reasonable to assume that a uniform temperature of $20^{\circ} \mathrm{C}$ is reached in the composite pipe without change of the moisture concentration (dry conditions). This change of temperature induced internal stresses which add to the residual manufacturing stresses. Fig. 2(a) shows the corresponding strength factor. Critical values of the strength factor, less to 1 , are reached for the pipe manufactured by using thick mandrels : one-third and one-fifth of the total thickness. To reduce the internal stress state a humid conditioning, temperature of $60{ }^{\circ} \mathrm{C}$ and a relative humidity of $50 \%$, is introduced before the placement at ambient conditions of the composite pipe. We check, in Fig. 2(b), that the change in temperature, from the temperature at the end of the cool-down (Fig. 1) to a uniform temperature of $60{ }^{\circ} \mathrm{C}$, no involves damage in the composite pipe for all the mandrels considered. The change of the moisture concentration from the dry conditions to a relative humidity of $50 \%$ produce compressive stresses 
which induced a growth of the strength factor (plotted in Fig. 3(a) for values less than 10). Fig. 3(b) depicted the strength factor, for values less than 10 , when the composite pipe is placed in the environmental conditions. The strength factor undergoes important gradients and it reaches a minimum value of about 2,75 on the inner surface. Finally, the material integrity is preserved by introducing transient hygrothermal stresses.

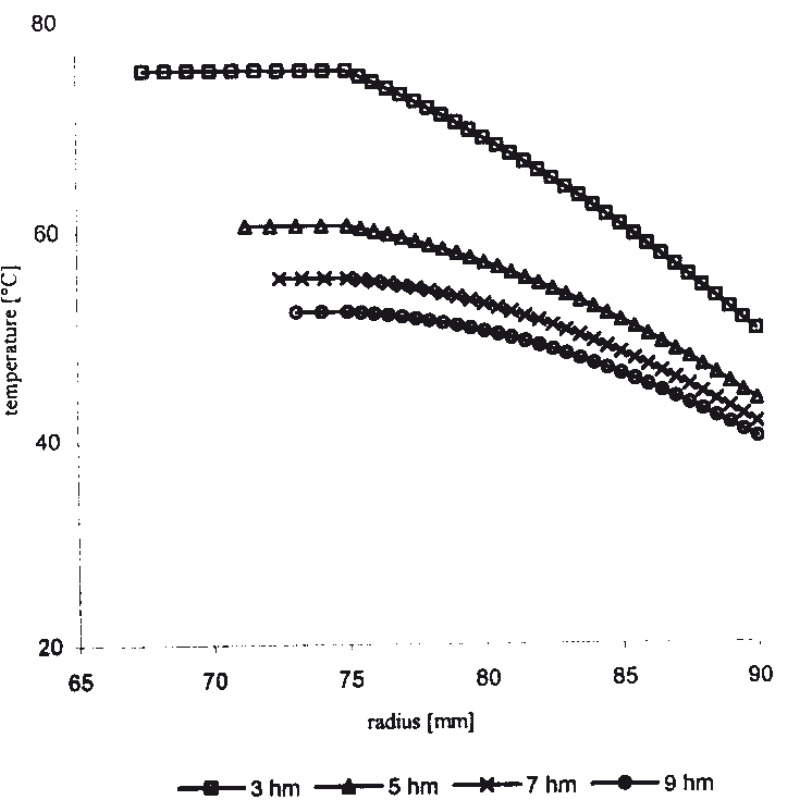

(a)

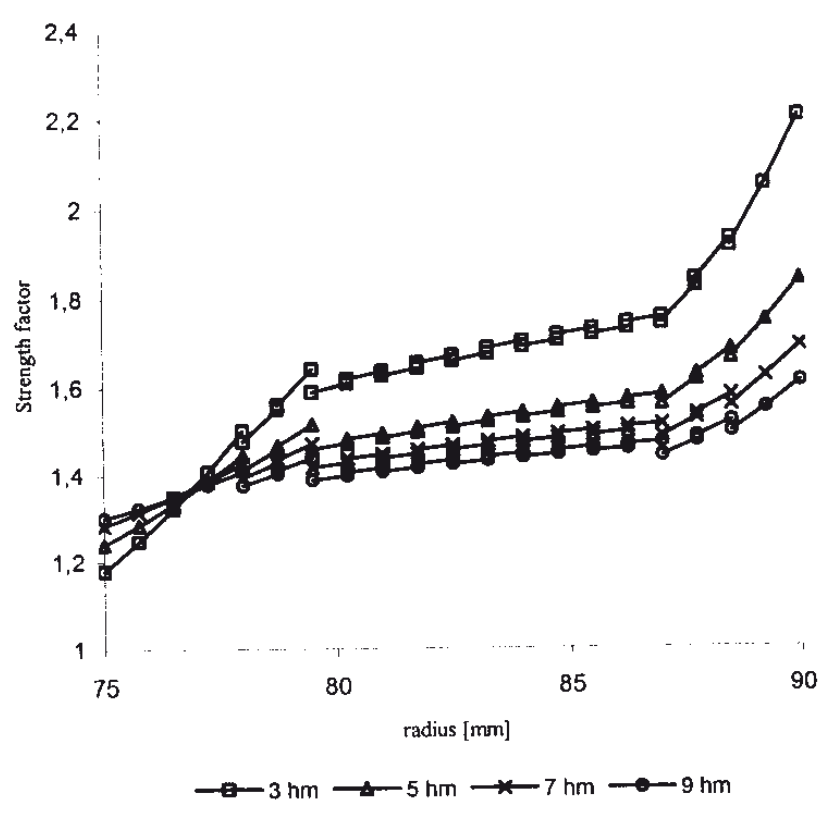

(b)

Figure 1 : At the end of the cool-down: (a) thermal fields, (b) strength factors

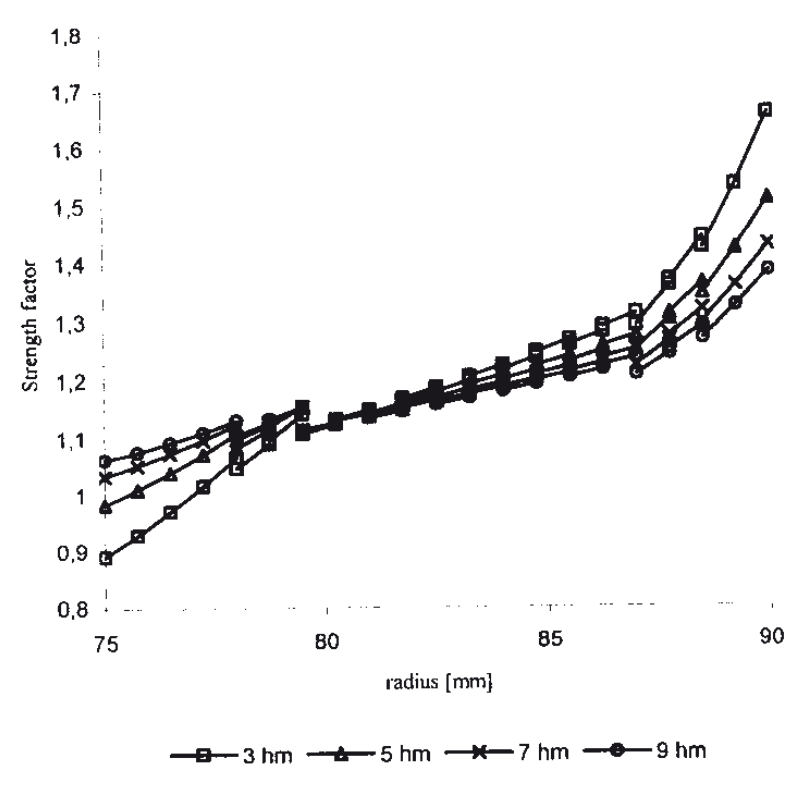

(a)

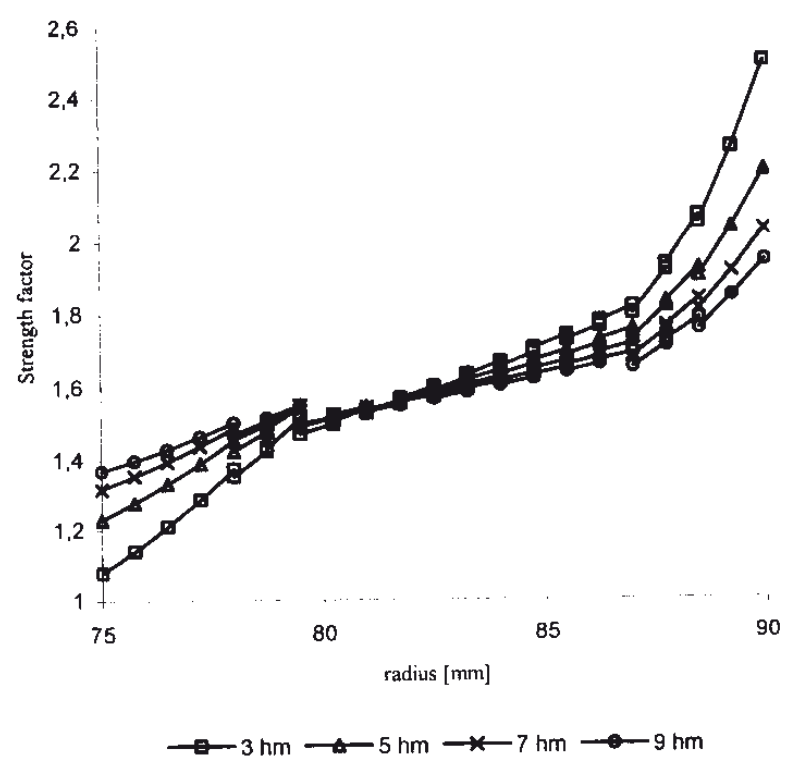

(b)

Figure 2 : Strength factors : (a) at $20^{\circ} \mathrm{C}$, (b) at $60^{\circ} \mathrm{C}$. 


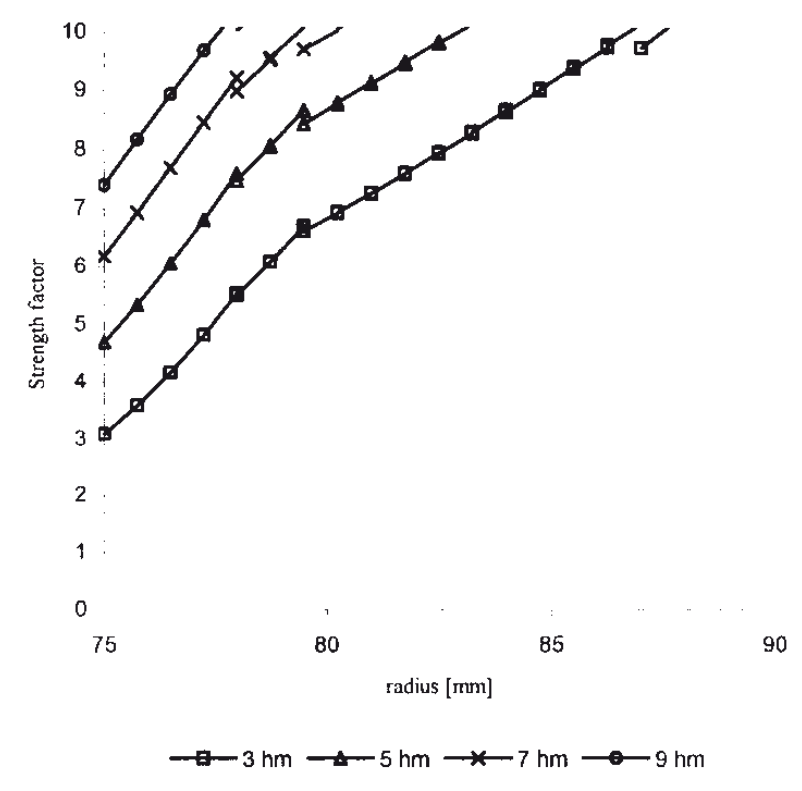

(a)

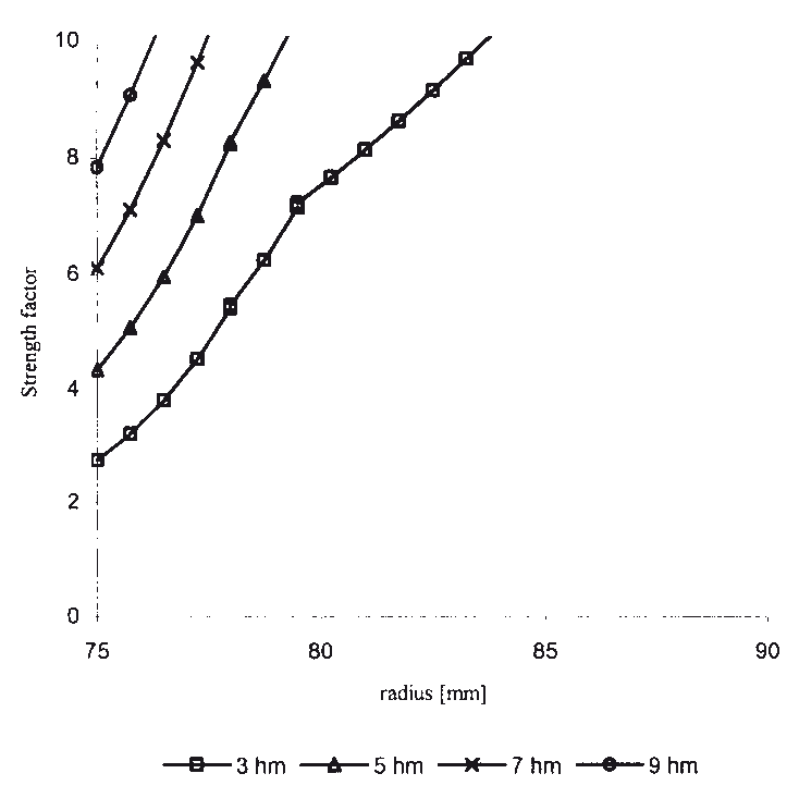

(b)

Figure 3 : Strength factors : (a) at $60{ }^{\circ} \mathrm{C}$ and $50 \% \mathrm{Hr}$, (b) at $20^{\circ} \mathrm{C}$ and $50 \% \mathrm{Hr}$.

\section{Conclusion}

The problem of internal stresses induced by processing and ambient conditions in thick polymer composite pipes is examined. The paper present an approach that allows to reduce the internal stress state and prevent process-induced damage by using a post-cure hygrothermal treatment. The growth of internal stresses, induced by the ambient conditions after the manufacturing process, can lead to damage for thick composite pipes. It is shown that the introduction of a humid conditioning, before the placement in the ambient conditions of the composite structure, involves a reduction of the internal stresses. The influence of the mandrel thickness on the residual stress development is investigated. It is emphasized that curing stresses can be manipulated by choosing tailored mandrel thickness.

\section{References}

[1] S.Y. Lee, G. S. Sringer and E.P. Calius: Jour. of Comp. Mater. Vol. 24 (1990), p. 1270.

[2] T.A. Bogetti and J.W. Gillespie: Jour. of Comp. Mater. Vol. 26 (1992), p. 626.

[3] M.R. Wisnom, L.G. Stringer, R.J. Hayman and M.J. Hinton: Proc. ICCM 12, Paris (1999).

[4] F. Jacquemin and A. Vautrin: Comp. Sci. and Tech. Vol. 62 (2002), p. 567.

[5] Y.K. Kim and S R White: Mech. of Comp. Mater. and Struc. Vol. 5 (1998), p. 327.

[6] S.W. Tsai: Composite design (Think composites, 1987). 